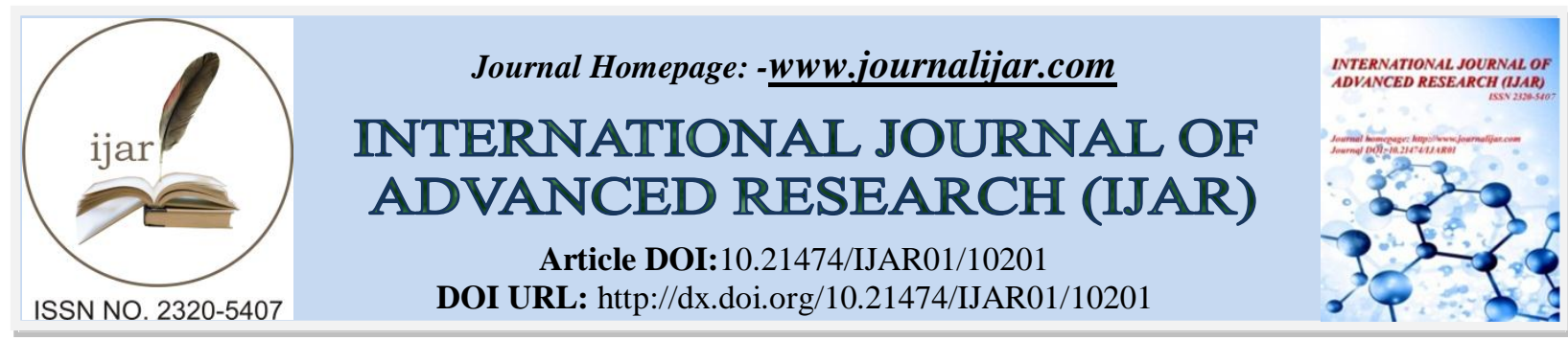

RESEARCH ARTICLE

\title{
RISK FACTORS FOR BREAST CANCER RECURRENCE : ABOUT 310 CASES
}

\begin{abstract}
Abdelhak Maghous ${ }^{1}$, Mohamed Elmarjany ${ }^{1}, \mathrm{EI}$ - Amin Marnouch ${ }^{1}$, Maroa Belemlih ${ }^{1}$, Mohcine Hommadi ${ }^{1}$, Noha Zaghba ${ }^{1}$, Khalid Andaloussi Saghir ${ }^{1}$, Baba Habib ${ }^{2}$, Jaouad Kouach ${ }^{2}$, Hassan Sifat ${ }^{1}$, Hamid Mansouri ${ }^{1}$ and Khalid Hadadi ${ }^{1}$

1. Department of Radiotherapy, Mohammed V Military Teaching Hospital, Mohammed V University in Rabat Morocco.

2. Department of Gynecology, Mohammed V Military Teaching Hospital, Mohammed V University in Rabat Morocco.
\end{abstract}

\section{Manuscript Info}

Manuscript History

Received: 10 October 2019

Final Accepted: 12 November 2019

Published: December 2019

Key words:-

Breast Cancer, Recurrence, Risk Factors

\section{Abstract}

Purpose: To retrospectively study our risk factors for breast cancer recurrence and compare them with data from the literature.

Materials and Methods: Through the analysis of 310 patients admitted to the radiotherapy department of the Mohammed V Military Teaching Hospital in Rabat between January 2009 and December 2015, we identified local, locoregional and / or systemic recurrence factors.

Results: The mean age was $49.15 \pm 10.37$ years, the mean parity was $3.3 \pm 2,43.5 \%$ were postmenopausal, $18.3 \%$ had a family history of breast cancer, and $41.3 \%$ used oral contraception. According to the TNM classification, $49.8 \%$ were classified as stage IIA. Invasive ductal carcinoma was predominant (82.6\%). For the histo-prognosis grade of Scarf-Bloom and Richardson (SBR), 91\% of patients were classified as SBR II and III. Lymphovascular invasion (LVI) were positive in $44.2 \%$, and hormone receptors (HR) were positive in $75.8 \%$. Lymph node involvement $\geq 4$ nodes was noted in $28.5 \%$ of patients. In univariate analysis, the presence of LVI $(p<0.001), \mathrm{N} \geq 4(\mathrm{p}<0.025)$ and RH negative $(\mathrm{p}<0.021)$ were statistically significant risk factors for recurrence. While in multivariate analysis, only EV ( $\mathrm{p}<0.035)$ and HR negativity $(\mathrm{p}<0.012)$ were statistically significant.

Conclusion: Our study highlights known risk factors; namely massive ganglionic invasion, lymphovascular invasion and hormone receptors. Other factors must be studied to improve the future management of our patients.

Copy Right, IJAR, 2019,. All rights reserved.

\section{Introduction:-}

According to GLOBOCAN 2018, breast cancer in women is one of the leading cancer in the world in terms of the number of new cases; approximately 2.1 million diagnoses are estimated in 2018 [1]. In Morocco, its frequency is constantly increasing to become the most common cancer in women, its incidence is estimated at 43.4 new cases per 100000 women per year, and therefore constitutes a real public health problem [2].

\section{Corresponding Author:- Abdelhak Maghous}

Address:- Department of Radiotherapy, Mohammed V Military Teaching Hospital, Mohammed V University in Rabat - Morocco. 
Breast cancer is a multifactorial disease, and several factors influence the risk of its occurrence. There are many prognostic factors, and each year new ones appear and others disappear. These same factors have been analyzed in several studies for their potential roles in local and systemic recurrence of breast cancer after treatment. Some have been the subject of a consensus about their contribution in relapse, such as age, Lymphovascular invasion (LVI), and surgical excision margins. Although, some factors are still controversial, such as the histological type, The ScarffBloom-Richardson (SBR) grade, initial tumor size, the presence of hormone receptor (HR) status, the presence of intraductal carcinoma, and the C-erbB-2 oncogene amplification[3].

In light of these data, and given the high frequency of breast cancer in our hospital, it was essential to think about studying these factors in relation to the risk of recurrence after treatment.

The aim of this work is to study the respective weight of each factor, in relation to the risk of recurrence and their effects in the recurrence of breast cancer, through a retrospective study of 310 patients in the department of radiotherapy in Mohammed V Military Teaching Hospital in Rabat.

\section{Material and Method:-}

\section{Study population:-}

This is a retrospective study conducted in Mohammed V Military Teaching Hospital in Rabat and included 310 patients admitted and regularly monitored by the department of radiotherapy-oncology from January 2010 to December 2015, of which 48 patients developed a local, locoregional and / or metastatic recurrence during their follow-up.

Data for each patient in the study were obtained from the medical records completed during their first admission. All clinical, paraclinical, anatomopathological, therapeutic and prognostic information has been collected by qualified professionals. These informations have been listed on an exploitation sheet.

\section{Statistical analysis:-}

Statistical analysis of the data was performed by SPSS 20 for Windows (SPSS, Inc., Chicago, IL, USA). Qualitative variables are presented in number and percentage. Quantitative variables are presented as mean \pm standard deviation for normal and median and interquartile range (IQR) for asymmetric distribution variables. To determine the risk factors, we applied regression analysis to determine the odds ratio and the $\mathrm{p}$ value for each factor in univariate and multivariate analysis. The test was considered significant when the $\mathrm{p}$ value $<0.05$.

\section{Results:-}

The average age of breast cancer reveal in our patients was $49.15 \pm 10.37$ years ( 2 - 84 years). The average age of menarche was $13.64 \pm 1.58$ years (10 - 18 years). The average age of first pregnancy was $21.78 \pm 5.44$ years (15 - 41 years). The average parity was 3.3 with $(0-13)$. In this population, $124(43.5 \%)$ patients were postmenopausal at the time of diagnosis. Oral contraception was noted in $128(41.3 \%)$ patients. A family history of breast cancer was recorded in $55(18.3 \%)$ patients. The median time to diagnosis of breast cancer was 3 [1-12] months, with extremes of 1 and 72 months. The median tumor size in the mammogram was $25 \mathrm{~mm}$ [19-33] with extremes of 15 and $70 \mathrm{~mm}$. Invasive ductal carcinoma was the most common histologic type since it was found in 251 (82.6\%) cases, followed by infiltrating lobular carcinoma in $12(3.9 \%)$ cases, and for the Scarff-Bloom-Richardson (SBR) histoprognostic grading, $63.8 \%$ of patients were classified SBR II, 27.2\% SBR III, and $8.7 \%$ were classified SBR I. Breast tumors were classified stage I in $27.1 \%$, stage IIA in $49.8 \%$ and stage IIB in $14.4 \%$. Hormonal receptors (HR) and HER2 status were investigated in all patients in our serie. HR was positive in $227(73.2 \%)$ patients, while HER2 was positive in $86(28.5 \%)$ patients. The median of Ki67 was 20 [10 - 38.75]. LVI were present in $126(44.2 \%)$ patients.

All patients underwent surgery (breast surgery + axillary dissection). The surgical margins were negatives in 301 $(98.7 \%)$ patients. The average number of lymph nodes $(\mathrm{LN})$ removed was $15 \pm 5.5$. Lymph node dissection was negative in $116(39.6 \%)$ patients, whereas node involvement of more than 4 lymph nodes ( $>$ or $=4 \mathrm{~N}+)$ was noted in $84(28.5 \%)$ patients, and less than $4(<4 \mathrm{~N}+)$ lymph nodes, in $95(32.2 \%)$ patients.

As adjuvant therapy: $268(86.7 \%)$ patients received adjuvant chemotherapy, 77 (26.6\%) patients received Trastuzumab treatment, and 298 (95.8\%) patients received local radiotherapy. 
Hormonal therapy was indicated in 227 (73.2\%) patients: it was Tamoxifen hormone therapy in 114 (50.2\%) patients, aromatases inhibitors in $80(35.2 \%)$ patients or switch protocol in the remaining $33(14.5 \%)$ patients. The median follow-up was 34 months [22; 48] with extremes of 1 and 97 months. All these descriptive results are reported in Table 1.

During the follow-up, 48 (15.5\%) patients developed local, locoregional and / or metastatic recurrence. Local and locoregional relapses were noted in $7(2.4 \%)$ patients, while $41(15.2 \%)$ patients had a distant relapse. The median time to relapse was 14 months [8-25], with extremes of 2 and 50 months.

The results of our analytical study of various risk factors for recurrence are reported in Tables 2 and 3 . The univariate analysis (Table 2) indicated that the presence of LVI, lymph node involvement $\geq 4$ and negative HR were statistically significant parameters influencing the occurrence of relapse in our serie. Moreover, multivariate analysis (Table 3) showed that absence of LVI and positive HR were associated with a lower risk of recurrence.

\section{Discussion:-}

Through this study, we tried to highlight the risk factors that seemed to influence local, locoregional and metastatic recurrence in our department. We noted that our relapse rate was a little higher than reported in the literature (15.5\% versus 8 to $9 \%$ ) [4,5]. We found a many common risk factors with those found in the literature,such as massive node invasion, the presence of LVI and the HR status. But other decisive factors do not emerge from our analysis.

Massive axillary lymph node involvement is often found as a risk factor for locoregional recurrence [6-9]. When the axillary or supraclavicular lymph nodes are invaded, the risk of relapse is greater than when the disease is localized to the breast. The risk increases with the number of lymph nodes affected. The absolute number of invading axillary lymph nodes is considered the most important prognostic factor in breast cancer. An accurate assessment of the axillary region is the basis of adjuvant treatment decision and prognostic assessment. Over the past decade, several studies have been published indicating that LNR (Lymph Node Ratio) may be a superior indicator of axillary tumor invasion and predict the outcome better than the number of positive LN. In the Van der Waal study [10], the 10-year survival of patients with LNR greater than or equal to 0.2 was $52 \%$, compared to $73 \%$ of patients with LNR less than $0.2(\mathrm{p}=0.0001)$. In the Kim.J study [11], the prognostic value of the LNR was evaluated in 144 patients, 130 of whom had a low LNR (0.01-0.15), and 14 patients had a high LNR (>0.15). The 5-year survival was $93.5 \%$ and $85.7 \%$ in the patients with low and high LNR respectively. A high LNR was associated with a poor prognosis in the univariate analysis $(\mathrm{p}<0.004)$ and the multivariate analysis $(\mathrm{OR}=3.453$ [1.273-9.361], $\mathrm{p}<0.015)$. The results of our work are consistent with these studies since $\mathrm{LN}$ involvement was a statistically significant factor of relapse, with $\mathrm{OR}=0.420[0.197-0.896]$ and $\mathrm{p}<0.025$ for $<4 \mathrm{~N}+$ and $\mathrm{OR}=0.223[0.097-0.513]$ and $\mathrm{p}<0.0004$ for $\geq 4 \mathrm{~N}+$ invasion.

The presence of LVI is also found to be a risk factor for locoregional recurrence by many authors [7,12-16]. This factor is particularly important in patients without lymph node involvement. It is reasonable to assume that the worst prognosis of LVI is related to the high level of tumor cell dissemination (metastasis). Young Du Song [17] demonstrated, through a retrospective study of 967 patients, that lymphovascular invasion (LVI) was a significant independent prognostic factor of disease-free survival (DFS) and overall survival (OS). In univariate analysis, 5-year OS and 5-year DFS were significantly different in patients with and without LVI: 88.8\% vs. 94.1\% (p = 0.007) for OS and $76.4 \% \%$ vs. $90.9 \%$ ( $p<0.001$ ) for DFS. In addition, survival without metastasis at 5 years was shorter in patients with LVI: $80.1 \%$ versus $91.5 \%$ compared to patients without LVI ( $p<0.001)$. In our serie, the presence of LVI had a significant effect on relapse with $\mathrm{OR}=0.343[0.17-0.66]$ and $\mathrm{p}<0.001$. This factor is noted in $66 \%$ of patients who had a recurrence.

The value of HR status for predicting the hormone sensitivity of tumors is no longer in doubt. On the other hand, their independent predictive value of relapse is variously appreciated in the literature. Patients with triple-negative breast cancer have an increased likelihood of distant recurrence and death compared to other profiles, and the difference persists after control with established prognostic factors. However, the recurrence patterns in both subgroups are qualitatively different. Patients with triple-negative breast cancer had high recurrence rates only 1 to 4 years after diagnosis. The risk then decreased rapidly and no recurrence occurred after 8 years of follow-up. In the other group, the risk of recurrence and death was stable and continued for 17 years after diagnosis [18]. The presence of hormone receptors was a significant factor in the multivariate analysis in our serie. The odds ratio was $\mathrm{OR}=2.525$ [1.223-5.217], and $\mathrm{p}<0.012$. Only 28 patients with positive hormone receptor relapses, compared to 199 without local or systemic recurrence. 
The age of patient, the histological SBR grading, the size of the tumor and the quality of margins are often associated with the risk of locoregional and distant recurrence according to several authors [19-22]. But, our numbers did not allow us to highlight this difference. Thus, all these factors were not identified in the univariate and multivariate analysis of our study.

Table 1:- Patient Characteristics.

\begin{tabular}{|c|c|c|}
\hline \multicolumn{2}{|c|}{ Patient Characteristics } & \\
\hline \multicolumn{2}{|l|}{ Age (years) } & $49,15 \pm 10,37$ \\
\hline \multicolumn{2}{|c|}{ Menarche (years) } & $13,64 \pm 1,58$ \\
\hline \multicolumn{2}{|c|}{ Average age of first pregnancy (years) } & $21,78 \pm 5,44$ \\
\hline \multicolumn{2}{|c|}{ Number of pregnant } & $3,9 \pm 2,34$ \\
\hline \multicolumn{2}{|c|}{ Parity } & $3,3 \pm 2$ \\
\hline \multirow[t]{2}{*}{ Contraception } & No & $55(17.7 \%)$ \\
\hline & Yes & $128(41.3 \%)$ \\
\hline \multirow[t]{2}{*}{ Menopause } & No & $161(56.5 \%)$ \\
\hline & Yes & $124(43.5 \%)$ \\
\hline Family history & & $55(18.3 \%)$ \\
\hline \multicolumn{2}{|c|}{ Diagnostic delay (month) } & $3[1-12]$ \\
\hline \multicolumn{2}{|c|}{ Tumor size in the mammogram $(\mathrm{mm})$} & 25 [19-33] \\
\hline \multirow[t]{8}{*}{ TNM Stage } & Tis & $3(1 \%)$ \\
\hline & $\mathbf{I}$ & $81(27.1 \%)$ \\
\hline & IIA & $149(49.8 \%)$ \\
\hline & IIB & $43(14.4 \%)$ \\
\hline & IIIA & $\begin{array}{c}5(1.7 \\
\%)\end{array}$ \\
\hline & IIIB & $8(2.7 \%)$ \\
\hline & IIIC & $2(0.7 \%)$ \\
\hline & IV & $8(2.7 \%)$ \\
\hline \multirow[t]{2}{*}{ Histologic type } & Invasive ductal carcinoma & $\begin{array}{l}251(8 \\
2.6 \%) \\
\end{array}$ \\
\hline & Others & $53(18.4 \%)$ \\
\hline \multirow[t]{3}{*}{ SBR } & $\mathbf{I}$ & $25(8.7 \%)$ \\
\hline & II & $183(63.8 \%)$ \\
\hline & III & $78(27.2 \%)$ \\
\hline \multirow[t]{2}{*}{ LVI } & No & $159(55.8 \%)$ \\
\hline & Yes & $126(44.2 \%)$ \\
\hline \multirow[t]{3}{*}{ LNR } & N0 & $116(39.6 \%)$ \\
\hline & $<4 \mathrm{~N}+$ & $95(32.2 \%)$ \\
\hline & $>0 r=4 N+$ & $84(28.5 \%)$ \\
\hline \multirow[t]{2}{*}{ Margins } & Negatives & $301(98.7 \%)$ \\
\hline & Positives & . \\
\hline \multirow[t]{2}{*}{$\mathrm{HR}$} & No & $83(26.8 \%)$ \\
\hline & Yes & $227(73.2 \%)$ \\
\hline \multirow[t]{2}{*}{ HER } & No & $216(71.5 \%)$ \\
\hline & Yes & $86(28.5 \%)$ \\
\hline \multirow[t]{2}{*}{ Ki67 } & $<20 \%$ & $34(44.7 \%)$ \\
\hline & $>$ or $=20 \%$ & $42(55.3 \%)$ \\
\hline \multicolumn{2}{|l|}{ Chemotherapy } & $268(86.7 \%)$ \\
\hline \multicolumn{2}{|c|}{ Hormonotherapy } & $227(73.2 \%)$ \\
\hline \multirow[t]{3}{*}{ Type of HTH } & Tamoxifen & $114(50.2 \%)$ \\
\hline & Aromatases inibitors & $80(35.2 \%)$ \\
\hline & Switch & $33(14.5 \%)$ \\
\hline \multicolumn{2}{|l|}{ HERCEPTIN } & $77(26.6 \%)$ \\
\hline
\end{tabular}


1. OR : Odds Ratio

2. CI : confidence interval

3. LNR : Lymph Node Ratio

4. HR: Hormone receptor

5. HTH : hormonal therapy

Table 2:- Univariate analysis of the different risk factors for breast cancer recurrence.

\begin{tabular}{|c|c|c|c|c|c|c|}
\hline \multirow{2}{*}{\multicolumn{2}{|c|}{ Factor of relapse }} & \multicolumn{2}{|c|}{ Relapse } & \multicolumn{3}{|c|}{ UnivariateAnalysis } \\
\hline & & Oui & Non & OR & $95 \% \mathrm{CI}$ & p Value \\
\hline \multicolumn{2}{|l|}{ Age (years) } & $47,8 \pm 10,25$ & $\begin{array}{c}49,36 \pm \\
10,36\end{array}$ & 0,987 & $0,985-1,017$ & 0,404 \\
\hline \multicolumn{2}{|l|}{ Menarche (years) } & $13,58 \pm 1,89$ & $\begin{array}{c}13,65 \pm \\
1,55\end{array}$ & 0,980 & $0,729-1,317$ & 0,894 \\
\hline \multicolumn{2}{|c|}{ Average age of first pregnancy (years) } & $23 \pm 5,96$ & $\begin{array}{c}22,03 \pm \\
5,00\end{array}$ & 0,953 & $0,824-1,060$ & 0,294 \\
\hline \multicolumn{2}{|c|}{ Number of pregnant } & $3,95 \pm 2,59$ & $\begin{array}{c}3,91 \pm \\
2,31\end{array}$ & 0,999 & $0,870-1,147$ & 0,990 \\
\hline \multicolumn{2}{|l|}{ Parity } & $3,3 \pm 2,16$ & $\begin{array}{c}3,31 \pm \\
2,01\end{array}$ & 0,996 & $0,850-1,168$ & 0,965 \\
\hline \multirow[t]{2}{*}{ Contraception } & No & $32(64,4 \%$ & $\begin{array}{c}43 \\
(16,4 \%)\end{array}$ & 1 & - & - \\
\hline & Yes & $16(35,6 \%$ & $\begin{array}{c}112 \\
(42,7 \%)\end{array}$ & 1,493 & $0,672-3,317$ & 0,325 \\
\hline \multirow[t]{2}{*}{ Menopause } & No & $28(62,2 \%$ & $\begin{array}{c}137 \\
(52,3 \%)\end{array}$ & 1 & - & - \\
\hline & Yes & $17(37,8 \%$ & $\begin{array}{c}106 \\
(40,5 \%)\end{array}$ & 1,032 & $0,532-1,999$ & 0,927 \\
\hline \multicolumn{2}{|c|}{ Diagnosticdelay (month) } & $2,50[1-12$ & $\begin{array}{l}7,67 \pm \\
11,28\end{array}$ & 1,002 & $0,974-1,032$ & 0,875 \\
\hline \multicolumn{2}{|c|}{ Tumor size in the mammogram) $(\mathrm{mm})$} & $30[20-48,5$ & $\begin{array}{c}23[18- \\
31]\end{array}$ & 1,005 & $0,992-1,017$ & 0,451 \\
\hline \multirow[t]{8}{*}{ TNM Stage } & Tis & $0(0 \%)$ & $3(1,1 \%)$ & 1 & - & - \\
\hline & $\mathbf{I}$ & $6(13,3 \%)$ & $\begin{array}{c}75 \\
(28,6 \%)\end{array}$ & $1,29.10^{8}$ & $0-0,001$ & 0,999 \\
\hline & IIA & $23(51,1 \%)$ & $\begin{array}{c}126 \\
(48,1 \%)\end{array}$ & $2,84.10^{8}$ & $0-0,001$ & 0,999 \\
\hline & IIB & $11(24,4 \%)$ & $\begin{array}{c}32 \\
(12,2 \%)\end{array}$ & $5,55.10^{8}$ & $0-0,001$ & 0,999 \\
\hline & IIIA & $2(4,4 \%)$ & $3(1,1 \%)$ & $1,09.10^{9}$ & $0-0,001$ & 0,999 \\
\hline & IIIB & $3(6,7 \%)$ & $5(1,9 \%)$ & $9,69.10^{8}$ & $0-0,001$ & 0,999 \\
\hline & IIIC & $0(0 \%)$ & $2(0,8 \%)$ & $9,69.10^{8}$ & $0-0,001$ & 0,999 \\
\hline & IV & $0(0 \%)$ & $5(1,9 \%)$ & 0,001 & $0-0,001$ & 0,999 \\
\hline \multirow[t]{2}{*}{ Histologic Type } & $\begin{array}{l}\text { Invasive ductal } \\
\text { carcinoma }\end{array}$ & $36(81,8 \%$ & $\begin{array}{c}212 \\
(80,9 \%)\end{array}$ & 1,157 & $0,585-2,288$ & 0,676 \\
\hline & Others & $8(18,2 \%)$ & $\begin{array}{c}45 \\
(17,2 \%)\end{array}$ & 1 & - & - \\
\hline \multirow[t]{3}{*}{ SBR } & I & $4(9,5 \%)$ & $21(8,0 \%)$ & 1 & - & - \\
\hline & II & $24(57,1 \%)$ & $157(59,9 \%)$ & 0,750 & $0,225-2,495$ & 0,639 \\
\hline & III & $14(33,3 \%)$ & $63(24,0 \%)$ & 0,652 & $0,328-1,297$ & 0,223 \\
\hline \multirow[t]{2}{*}{ LVI } & No & $16(36,4 \%)$ & $143(54,6 \%)$ & 1 & - & - \\
\hline & yes & $28(63,6 \%)$ & $95(36,3 \%)$ & 0,343 & $0,178-0,661$ & 0,001 \\
\hline \multirow[t]{3}{*}{ LNR } & No & $8(17,8 \%)$ & $107(40,8 \%)$ & 1 & - & - \\
\hline & $<\mathbf{4 N}+$ & $12(26,7 \%)$ & $82(31,3 \%)$ & $\mathbf{0 , 2 2 3}$ & $0,097-0,513$ & 0,0004 \\
\hline & $>$ or $=4 \mathrm{~N}+$ & $21(46,7 \%)$ & $61(23,3 \%)$ & 0,420 & $0,197-0,896$ & $\mathbf{0 , 0 2 5}$ \\
\hline
\end{tabular}




\begin{tabular}{|c|c|c|c|c|c|c|}
\hline \multirow[t]{2}{*}{ Margins } & Negatives & $43(95,6 \%)$ & $255(97,3 \%)$ & 1 & - & - \\
\hline & Positives & & $4(1,5 \%)$ & $2,91.10^{8}$ & 0,0001 & 0,999 \\
\hline \multirow[t]{2}{*}{ HR } & No & $17(37,8 \%)$ & $55(21,0 \%)$ & 1 & - & - \\
\hline & Yes & $28(62,2 \%)$ & $199(76,0 \%)$ & 2,171 & $1,126-4,184$ & $\mathbf{0 , 0 2 1}$ \\
\hline \multirow[t]{2}{*}{ HER } & No & $32(71,1 \%)$ & $181(69,1 \%)$ & 1 & - & - \\
\hline & Yes & $13(28,9 \%)$ & $73(27,9 \%)$ & 1,086 & $0,543-2,170$ & 0,816 \\
\hline \multirow[t]{2}{*}{ Ki67 } & $<20 \%$ & $4(40 \%)$ & $30(45,45 \%)$ & 1 & - & - \\
\hline & >or $=20 \%$ & $6(60 \%)$ & $36(54,55 \%)$ & 1,005 & $0,972-1,040$ & 0,762 \\
\hline \multicolumn{2}{|l|}{ Chemotherapy } & $43(95,6 \%)$ & $222(84,7 \%)$ & 0,247 & $0,058-1,061$ & 0,060 \\
\hline \multicolumn{2}{|c|}{ Hormonotherapy } & $26(57,8 \%)$ & $198(75,6 \%)$ & 2,655 & $1,399-5,040$ & $\mathbf{0 , 0 0 3}$ \\
\hline \multirow[t]{3}{*}{ Type of HTH } & Tamoxifen & $19(67,9 \%)$ & $90(34,4 \%)$ & 1 & - & - \\
\hline & $\begin{array}{l}\text { Aromatases } \\
\text { inibitors }\end{array}$ & $7(25 \%)$ & $64(24,4 \%)$ & 3,100 & $0,680-14,129$ & 0,144 \\
\hline & Switch & $2(7,1 \%)$ & $31(11,8 \%)$ & 1,453 & $0,277-7,618$ & 0,658 \\
\hline \multicolumn{2}{|l|}{ HERCEPTIN } & $12(27,9 \%)$ & $65(24,8 \%)$ & 0,993 & $0,484-2,038$ & 0,985 \\
\hline
\end{tabular}

Table 3:-Multivariate study of different risk factors for breast cancer recurrence.

\begin{tabular}{|c|c|c|c|c|}
\hline \multicolumn{2}{|c|}{ Factor } & \multicolumn{3}{c|}{ MultivariateAnalysis } \\
\cline { 3 - 5 } & & Odds Ratio & CI 95\% & p Value \\
\hline \multicolumn{2}{|c|}{ LVI } & $\mathbf{0 , 4 5 1}$ & $\mathbf{0 , 2 1 6 - 0 , 9 4 4}$ & $\mathbf{0 , 0 3 5}$ \\
\hline \multirow{2}{*}{ LNR } & $<\mathbf{4 N +}$ & 0,604 & $0,183-1,997$ & 0,409 \\
\cline { 2 - 5 } & $>/=4 N+$ & 0,609 & $0,267-1,388$ & 0,238 \\
\hline \multicolumn{2}{|c|}{ HR } & $\mathbf{2 , 5 2 5}$ & $\mathbf{1 , 2 2 3 - 5 , 2 1 7}$ & $\mathbf{0 , 0 1 2}$ \\
\hline
\end{tabular}

\section{Conclusion:-}

In total, the analysis of the risk factors of 310 breast cancer cases treated in the Mohamed V Military Teaching Hospital in Rabat, highlights known risk factors consistent with the data from the literature; such as; massive node invasion, presence of LVI and HR status. These factors are well used in the various current algorithms of adjuvant treatment decision in order to build a better therapeutic strategy of breast cancer management more and more targeted.

Ethics approval and consent to participate:-

Informed consent (verbal) was obtained from all participants. This study was submitted to and approved by research and ethics committee of military teaching hospital Mohamed V

\section{Competing interests:-}

We (authors) declare that we have no conflict of interest.

\section{Authors' Contribution:-}

Abdelhak Maghous and Mohamed Elmarjany, performed research and share the first position in this manuscript; A.M and M.E analyzed data statistically and drafted the manuscript; E.M, K.A, K.H, H.S, N.Z, J.H, B.H and H.M, designed and coordinated research and drafted the manuscript. All authors read and approved the final manuscript.

\section{Acknowledgement:-}

All the authors are thankful for providing the necessary facilities for the preparation the manuscript. Special thanks are due to the Faculty of Medicine and Pharmacy of Rabat; the source(s) of funding for all authors.

\section{References:-}

1. Bray F, Ferlay J, Soerjomataram I, Siegel RL, Torre LA, Jemal A. Global cancer statistics 2018: GLOBOCAN estimates of incidence and mortality worldwide for 36 cancers in 185 countries. CA Cancer J Clin. 2018 Nov;68(6):394-424.

2. Tazi MA, Er-Raki A, Benjaafar N. Cancer incidence in Rabat, Morocco: 2006-2008. E cancer medical science 2013;7:338-50. 
3. Fitzgibbons PL, Page DL, Weaver D, Thor AD, Allred DC, Clark GM et al. Prognosticfactors in breast cancer. College of American Pathologists Consensus Statement 1999.Arch Pathol Lab Med 2000; 124 : 966-978

4. Clarke M, Collins R, Darby S, Davies C, Elphinstone P, Evans E, et al., Early Breast Cancer Trialists' Collaborative Group(EBCTCG). Effects of radiotherapy and of differences in theextent of surgery for early breast cancer on local recurrenceand 15-year survival: an overview of the randomisedtrials.Lancet 2005;366:2087-106.

5. Grills IS, Kestin LL, Goldstein N, Mitchell C, Martinez A, Ingold J, et al. Risk factors for regional nodal failure after breast-conserving therapy: regional nodal irradiation reduces rate ofaxillary failure in patients with four or more positive lymphnodes. Int J RadiatOncolBiolPhys 2003;56:658 - 70.

6. Truong PT, Olivotto IA, Kader HA, Panades M, SpeersCH,Berthelet E. Selecting breast cancer patients with T1-T2tumors and one to three positive axillary nodes at highpostmastectomylocoregional recurrence risk for adjuvantradiotherapy. Int J RadiatOncolBiolPhys 2005;61:1337-47.

7. Kim KJ, Huh SJ, Yang JH, Park W, Nam SJ, Kim JH, et al.Treatment results and prognostic factors of early breast cancertreated with a breast conserving operation and radiotherapy.Jpn J ClinOncol 2005;35:126-33.

8. Komoike Y, Akiyama F, Iino Y, Ikeda T, Tanaka-Akashi S,Ohsumi S, et al. Analysis of ipsilateral breast tumor recurrencesafter breast-conserving treatment based on the classificationof true recurrences and new primary tumors. Breast Cancer2005;12:104-11.

9. Dunst J, Steil B, Furch S, Fach A, LautenschlagerC,Diestelhorst A, et al. Prognostic significance of local recurrencein breast cancer after postmastectomy radiotherapy. StrahlentherOnkol 2001;177:504-10.

10. Van Der Wal BC, Butzelaar RM, Van Der Meij S, Boermeester MA. Axillary lymph node ratio and total number of removedlymph nodes: predictors of survival in stage I and II breast cancer.Eur J SurgOncol. 2002;28:481-9.

11. Kim J, Kim JH, Kim OB, Oh YK, Park SG. Clinical significance of the lymph node ratio in N1 breast cancer.RadiatOncol J. 2017;35(3):227-232.

12. Cheng JC, Chen CM, Liu MC, Tsou MH, Yang PS, Jian JJ, et al. Locoregional failure of postmastectomy patients with 1-3 positive axillary lymph nodes without adjuvant radiotherapy. IntJRadiatOncolBiolPhys 2002;52:980-8.

13. Truong PT, Olivotto IA, Speers CH, Wai ES, BertheletE,Kader HA. A positive margin is not always an indication forradiotherapy after mastectomy in early breast cancer. IntJRadiatOncolBiolPhys 2004;58:797804.

14. Truong PT, Lesperance M, Culhaci A, Kader HA, SpeersCH,Olivotto IA. Patient subsets with T1-T2, nodenegative breastcancer at high locoregional recurrence risk after mastectomy.Int J RadiatOncolBiolPhys 2005;62:175-82.

15. Truong PT, Yong CM, Abnousi F, Lee J, Kader HA, Hayashi A,et al. Lymphovascular invasion is associated with reduced locoregional control and survival in women with node-negativebreast cancer treated with mastectomy and systemic therapy.J Am CollSurg 2005;200:912 - 21.

16. Veronesi U, Cascinelli N, Mariani L, Greco M, Saccozzi R, Luini A, et al. Twenty-year follow-up of a randomized studycomparing breast-conserving surgery with radical mastectomy for early breast cancer. $\mathrm{N}$ Engl J Med 2002;347:1227-32.

17. Song YJ, Shin SH, Cho JS, Park MH, Yoon JH, Jegal YJ. The role of lymphovascular invasion as a prognostic factor in patients with lymph node-positive operable invasive breast cancer.J Breast Cancer. 2011;14(3):198203.

18. Dent R, Trudeau M, Pritchard KI, Hanna WM, Kahn HK, Sawka CA, et al. Triple-negative breast cancer: clinical features and patterns of recurrence. Clinical cancer research : an official journal of the American Association for Cancer Research. 2007;13(15 Pt 1):4429-34.

19. Leong C, Boyages J, Jayasinghe UW, Bilous M, Ung O, Chua B, et al. Effect of margins on ipsilateral breast tumor recurrence after breast conservation therapy for lymph node-negative breast carcinoma. Cancer 2004;100:1823-32

20. Freedman G, Fowble B, Hanlon A, Nicolaou N, Fein D, Hoffman J, et al. Patients with early stage invasive cancer withclose or positive margins treated with conservative surgery andradiation have an increased risk of breast recurrence that isdelayed by adjuvant systemic therapy. Int J RadiatOncolBiolPhys 1999;44:1005—15.

21. Freedman GM, Fowble BL, Hanlon AL, Myint MA, Hoffman JP,Sigurdson ER, et al. A close or positive margin after mastectomy is not an indication for chest wall irradiation exceptin women aged fifty or younger. Int $\mathbf{J}$ RadiatOncolBiolPhys1998;4:599-605.

22. Meric F, Mirza NQ, Vlastos G, Buchholz TA, KuererHM,Babiera GV, et al. Positive surgical margins and ipsilateralbreast tumor recurrence predict disease-specific survival afterbreast-conserving therapy. Cancer 2003;97:926-33. 